\title{
Gypsum composition with siltstone-based mineral modifier
}

\author{
Grigory Yakovlev $^{1}$, Anastasiya Gordina ${ }^{2}$, Vladimir Khritankov ${ }^{3}$, \\ Vadim Khozin $^{4}$, Arina Shaybadullina ${ }^{5}$, Damir Khazeev ${ }^{6}$, Irina Bazhenova ${ }^{7}$, \\ Anna Ivakina $^{8}$, Zarina Saidova ${ }^{9}$, Alexander Repin $^{10}$ \\ ${ }^{1,2,5-10}$ V.A. Shumilov Institute of Construction and Architecture, Kalashnikov Izhevsk State Technical University, \\ Izhevsk, Russia \\ ${ }^{3}$ Department of Theoretical and Applied Physics, Novosibirsk State Agrarian University, Novosibirsk, Russia \\ ${ }^{4}$ Department of Building Materials Technologies Products and Designs, Kazan State University of Architecture \\ and Engineering, Kazan, Russia \\ E-mail: 'gyakov@istu.ru (corresponding author)
}

\begin{abstract}
The paper presents the results of studies of the structure and properties of the gypsum composition comprising 3\% of crushed siltstone, a metamorphic rock. The structure and physicochemical properties of siltstone were studied, which predetermine its usage as a structuring additive in gypsum compositions. Adding crushed siltstone to the composition of a gypsum binder is shown to cause the compaction of the structure of the gypsum matrix due to changes in the morphology of crystalline hydrates of calcium sulfate and monolithic structure in general, and, consequently, the enhanced mechanical characteristics of the gypsum composition. Using scanning electron microscopy, differential thermography, and IR spectral analysis explain the change in the physicomechanical properties of the gypsum binder.
\end{abstract}

Keywords: siltstone, gypsum composition, microstructure, pozzolans.

\section{Introduction}

In order to improve physical and technical properties of gypsum binders, such as strength, water resistance, and durability, modern materials science suggests a wide use of mineral and organic modifiers (Petropavlovskaya, Buryanov, Novichenkova, \& Petropavlovskii, 2018a, 2018b; Kondratieva, Barre, Goutenoire, \& Sanytsky, 2017; Arikan \& Sobolev, 2002; Flores Medina, Barbero-Barrera, \& Bustamante, 2016; Flores Medina \& Barbero-Barrera, 2017). Adding additives of mineral origin to the gypsum binder is considered one of the available ways to control its properties and the structure of gypsum rock. Currently, gypsum compositions have mainly foreign additives, which are quite expensive, and this determines the cost of the dry mix as a whole. At the same time, Russia has significant reserves of many mineral resources that can be used in the production of gypsum binders and compositions based on them. The additives used allow changing the morphology of gypsum crystalline hydrates, up to the formation on their surface of amorphous structures based on, above all, calcium hydrosilicates (Pervyshin et al. 2016), which protect the gypsum crystals from the direct effect of water molecules, fill intercrystallite pores while tying gypsum crystals into an agglomerate of increased density. This leads to the complication and change in the course of physicochemical processes that occur during the self-organization of the structure of gypsum rock at the stage of the formation of its crystallization framework.

According to (Solomatov \& Vyrova, 1984), an important role is played by the surface activity of the filler and the average size of its grains. It is noted that adding a filler with a particle size close to the size of the hydrated binder grains leads to a decrease in the strength of gypsum compositions. Fillers with a large particle size, "5-10 times larger than the size of elementary structural elements of the binder, allow controlling the mechanism of organizing at all stages of the formation of the spatial framework" (Samokhina, 2007). The role of the filler in this case is reduced to the substrate, on which the products of new formations diffuse.

As a rule, in most cases, during hardening of gypsum compositions, mineral modifiers contain pozzolanic components, which, in combination with lime-based or Portland cement-based alkalies, form water-resistant new formations, which not only increase their water resistance but also improve the mechanical properties of gypsum composite materials. Among the known mineral modifiers, metakaolin, which is a product of heat treatment of kaolin clays, has been frequently used recently (Segodnik \& Potapova, 2014; Zinin \& Sycheva, 2017). 
Possible natural modifiers of the structure of gypsum binders are shales, which are argillites containing clay minerals that have gone through geological metamorphization due to increased pressure and temperature at great depths. It should be noted that the development of argillite deposits will require significant costs for stripping and extracting this raw material. Siltstone can serve as a more acceptable variant of a mineral additive with inclusions of dehydrated clay minerals.

\section{Materials and methods}

Siltstone is a microfragmental sedimentary rock (Figure 1a) $50 \%$ or more consisting of cemented mineral fragments with a grain size from 0.1 to $0.01 \mathrm{~mm}$ with mica inclusions (Figure 1b). The cementing substances are amorphous silica and calcium carbonate. Siltstone is characterized by thin horizontal stratification with siltstone and clay layers interleaving (Figure 1a).

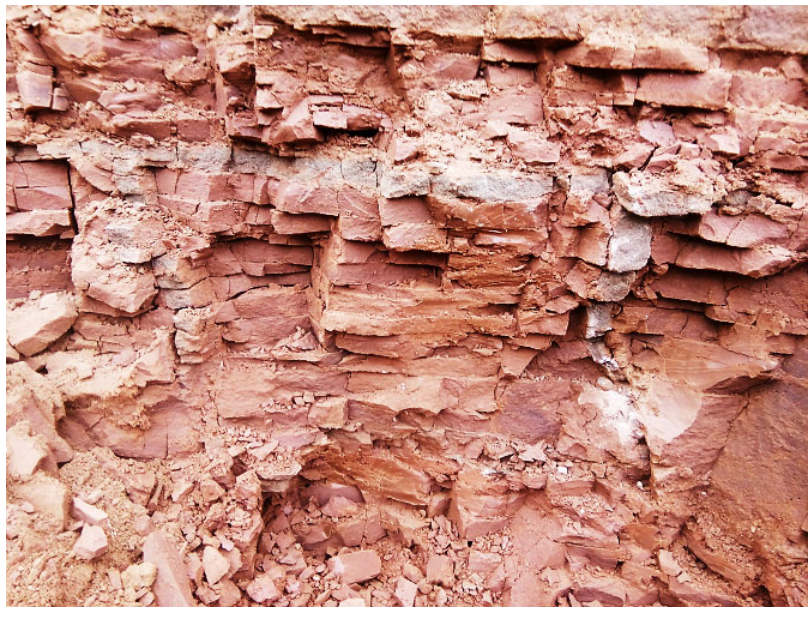

a)

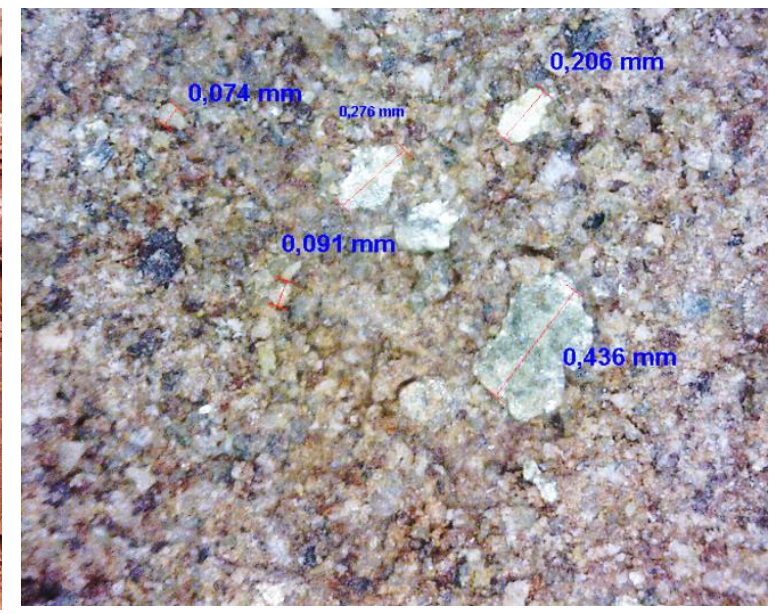

b)

Figure 1. Siltstone: (a) - general view of siltstone in a quarry with layers of white clay;

(b) - macrostructure of siltstone with mica inclusions

During the experiments, natural siltstone was crushed in a JC-6 jaw crusher, followed by grinding in a DG-200 disc grinder. The particle size analysis (Figure 2) of the additive was carried out with a SALD-7500 nanolaser dispersion analyzer and showed that the average particle size is $34.5 \mu \mathrm{m}$ and there is a nanometer component with an average particle size of $130 \mathrm{~nm}$.

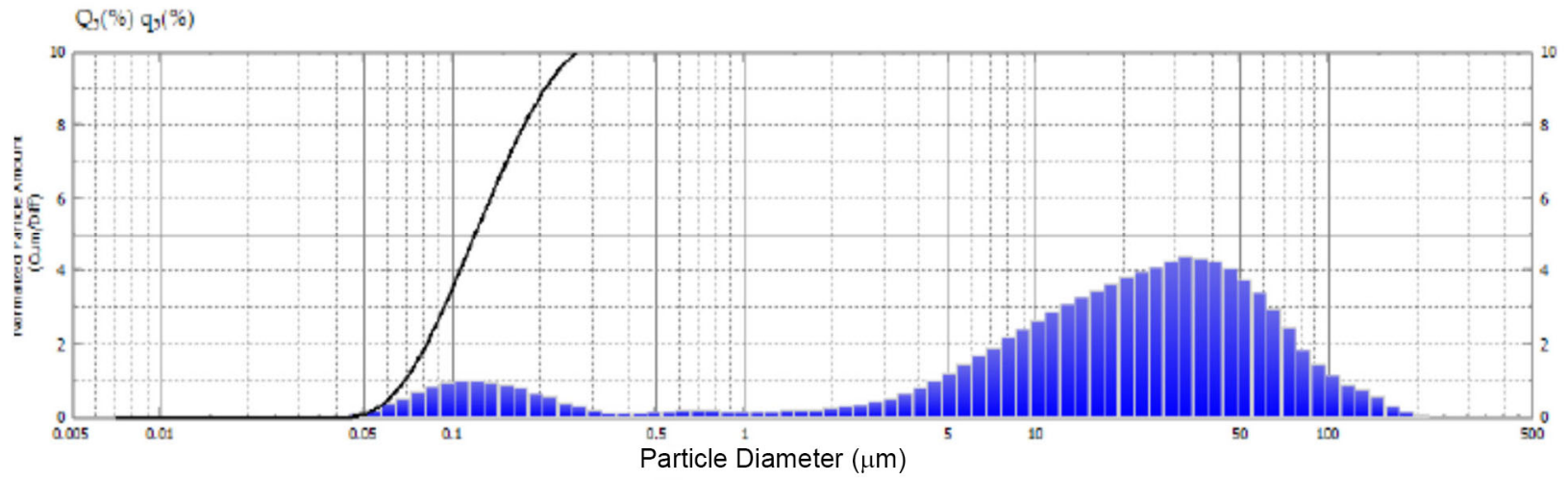

Figure 2. Analysis of siltstone particle size

Gypsum plaster of G-4 grade produced by Gipsopolymer (Perm) and corresponding to GOST 125-79 was used as a gypsum binder.

The macrostructure of siltstone was studied with a USB microscope at a 200-fold magnification. The microstructure of siltstone and gypsum composition were studied with a MIRA3 TESCAN microscope at the AdMaS research center of the Technical University of Brno.

X-ray phase analysis was conducted with a general DRON-3 diffractometer in Bragg-Brentano mode in CuK $\mathrm{K}_{\alpha}$ radiation monochromatized with graphite monochromator crystal, powder diffraction technique being used. 
Differential scanning calorimetry of siltstone was conducted with a TGA/DSC-1 derivatograph produced by Mettle Toledo.

IR spectroscopy of the gypsum composition was conducted in the frequency range of $4000 \div 400 \mathrm{~cm}^{-1}$ with an IRAffinity-1 FT spectrometer produced by Shimadzu.

To prepare gypsum samples, standard steel molds with dimensions of $40 \times 40 \times 160 \mathrm{~mm}$ were used. The gypsum samples were cured in the molds for 20-30 minutes, followed by mechanical strength tests. The samples were stored at temperature $\mathrm{T}=20^{\circ} \mathrm{C}$ for 7 days under conditions of normal humidity.

\section{Results and discussion}

The microstructure of siltstone (Figure 3a) includes particles of quartz sand, feldspar, and mica (Figure 3b), held together with clay inclusions. Calcium carbonate was found during field analysis (the reaction to a solution of hydrochloric acid with carbon dioxide emission).

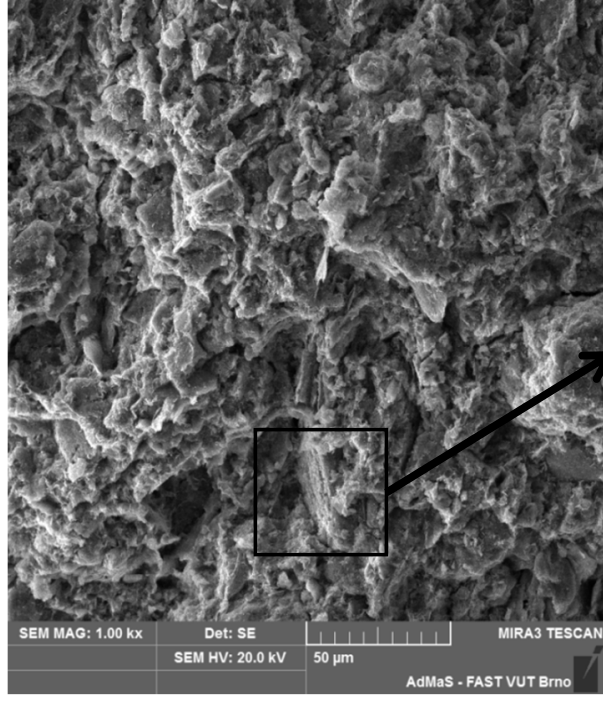

a)

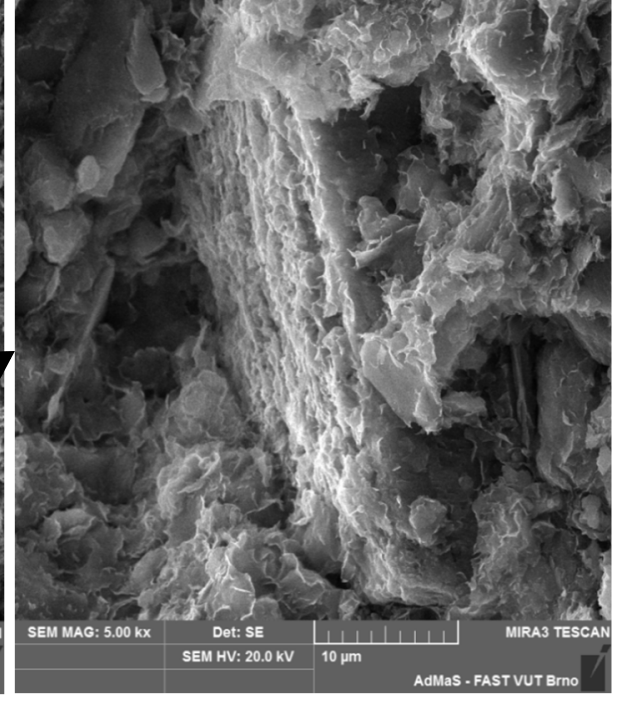

b)

Figure 3. Microstructure of siltstone: (a) - general view of siltstone at a 1000-fold magnification;

(b) - a fragment of microstructure with mica inclusions at a 5000-fold magnification

The conducted X-ray microanalysis (Figure 4b) of lamellar structures on the cleaved sample of siltstone showed the presence of atoms of silicon $\mathrm{Si}$, aluminum $\mathrm{Al}$, and oxygen $\mathrm{O}$, which suggests that clay minerals are included in the composition of siltstone.

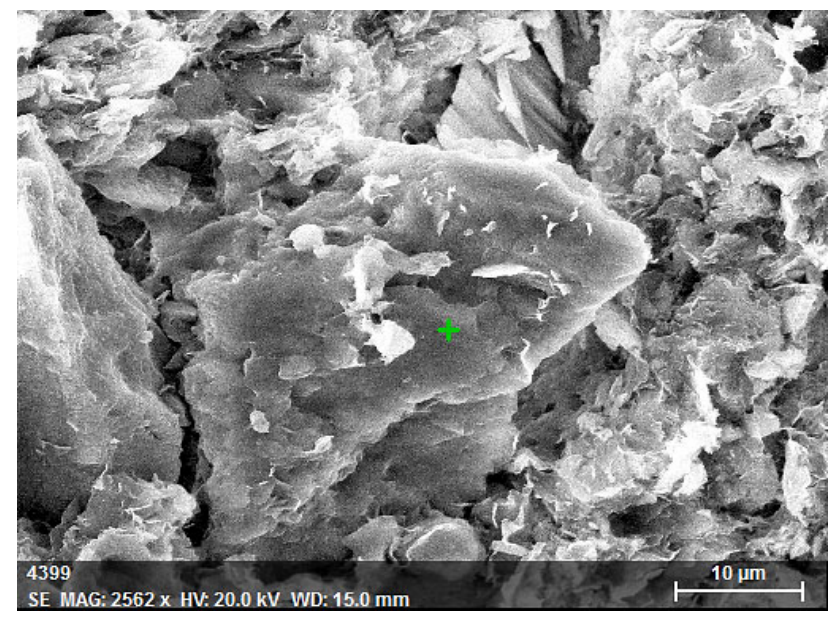

a)

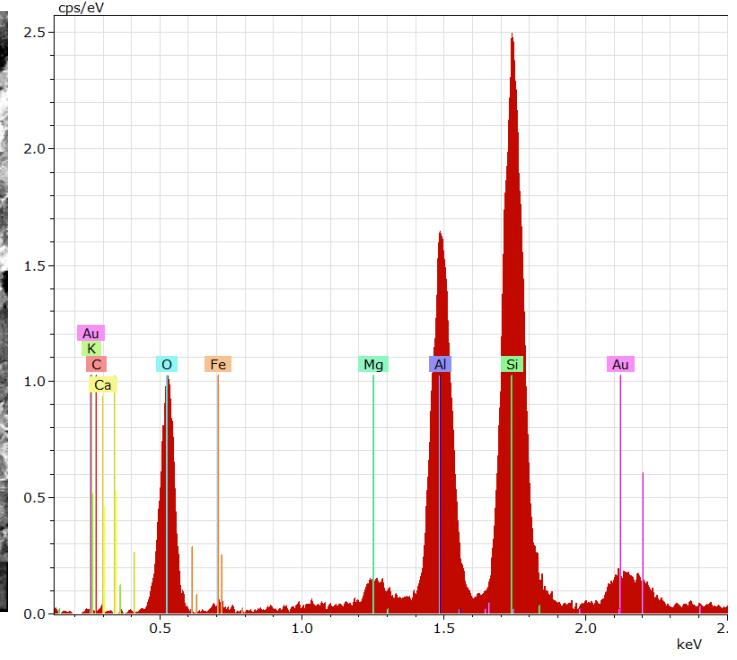

b)

Figure 4. X-ray microanalysis of siltstone: (a) - clay inclusions;

(b) - chemical composition of a fragment of siltstone microstructure 
X-ray phase analysis (Figure 5) of siltstone conducted with a general diffractometer DRON-3 showed the presence of the most intense reflection lines on the spectrum, corresponding to crystalline silicon oxide $\mathrm{SiO}_{2}\left(\mathrm{~d}_{\alpha}=4,26\right.$ $\AA$; $2,46 \AA ; 2,28 \AA ; 2,13 \AA ; 1,98 \AA ; 1,82 \AA ⿻ 11,67 \AA ; 1,54 \AA ; 1,45 \AA ; 1,38 \AA)$, vermiculite $\left(\mathrm{d}_{\alpha}=14,35 \AA ; 6,36 \AA ; 3,49\right.$ $\AA)$, kaolinite $\mathrm{Al}_{2} \mathrm{O}_{3} \cdot 2 \mathrm{SiO}_{2} \cdot 2 \mathrm{H}_{2} \mathrm{O}\left(\mathrm{d}_{\alpha}=7,16 \AA ; 4,50 \AA ; 3,34 \AA ; 3,19 \AA ; 2,70 \AA ; 2,56 \AA ; 2,33 \AA ; 1,37 \AA\right)$, calcite Ca$\mathrm{CO}_{3}\left(\mathrm{~d}_{\alpha}=3,03 \AA\right)$. In the spectrum in the area $2 \Theta=20-44$ degrees, the peaks are "blurred", which means there is an amorphous phase in the siltstone composition.

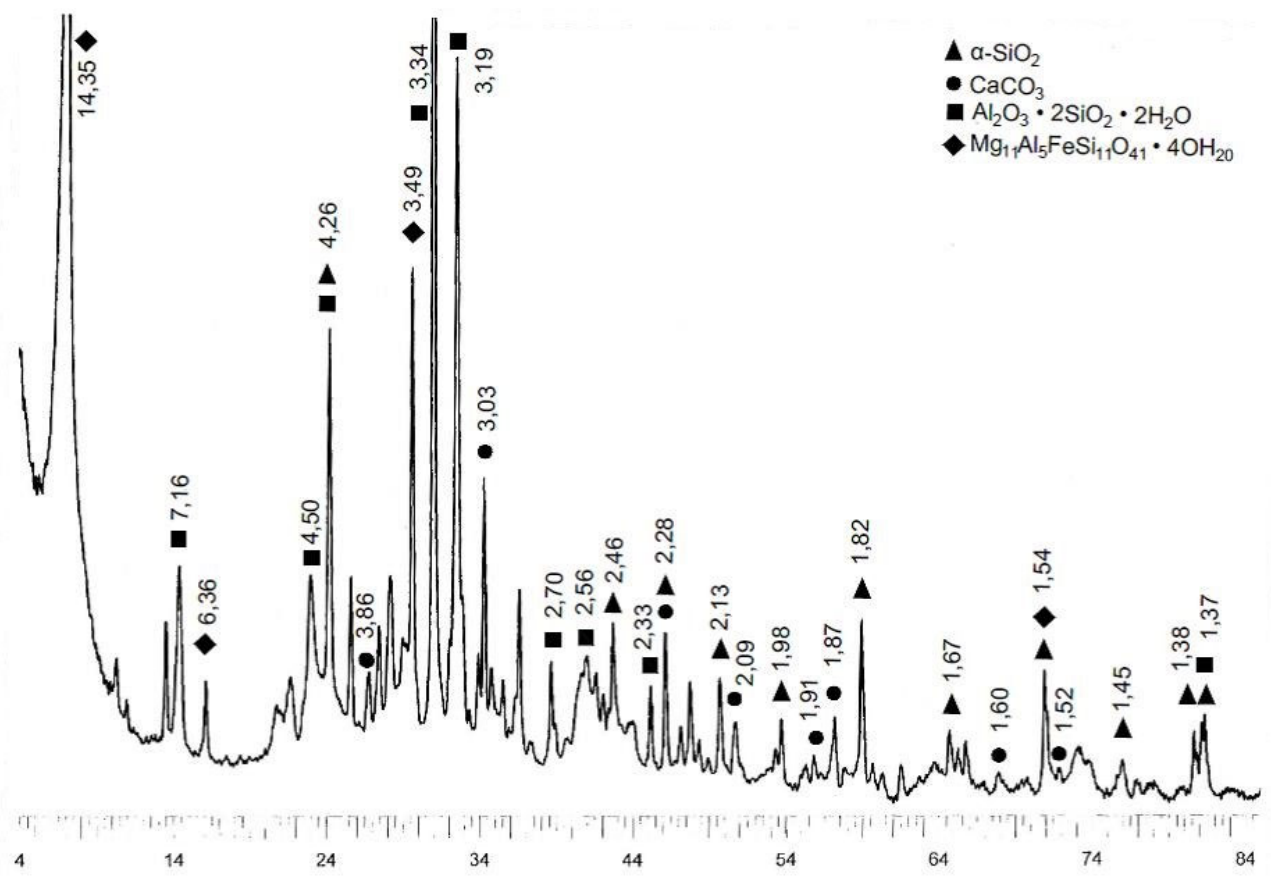

Figure 5. X-ray phase analysis of siltstone

Differential thermal analysis (Figure 6) of siltstone confirmed the presence of crystalline hydrate water in the additive composition (endo effects at temperatures of 166 and $220^{\circ} \mathrm{C}$ ). The organic component is present in the siltstone composition (exo effect at $380^{\circ} \mathrm{C}$ ). The endo effect at a temperature of $596.5^{\circ} \mathrm{C}$ is associated with the formation of metakaolinite during the destruction of the kaolinite crystal lattice. At a temperature of $829.5{ }^{\circ} \mathrm{C}$, the endothermic effect with simultaneous loss of water on the TG line is associated with the removal of combined water from vermiculite and the decomposition of calcium carbonate. At a temperature of $915^{\circ} \mathrm{C}$, mullite is formed due to recrystallization of amorphous silica and alumina.

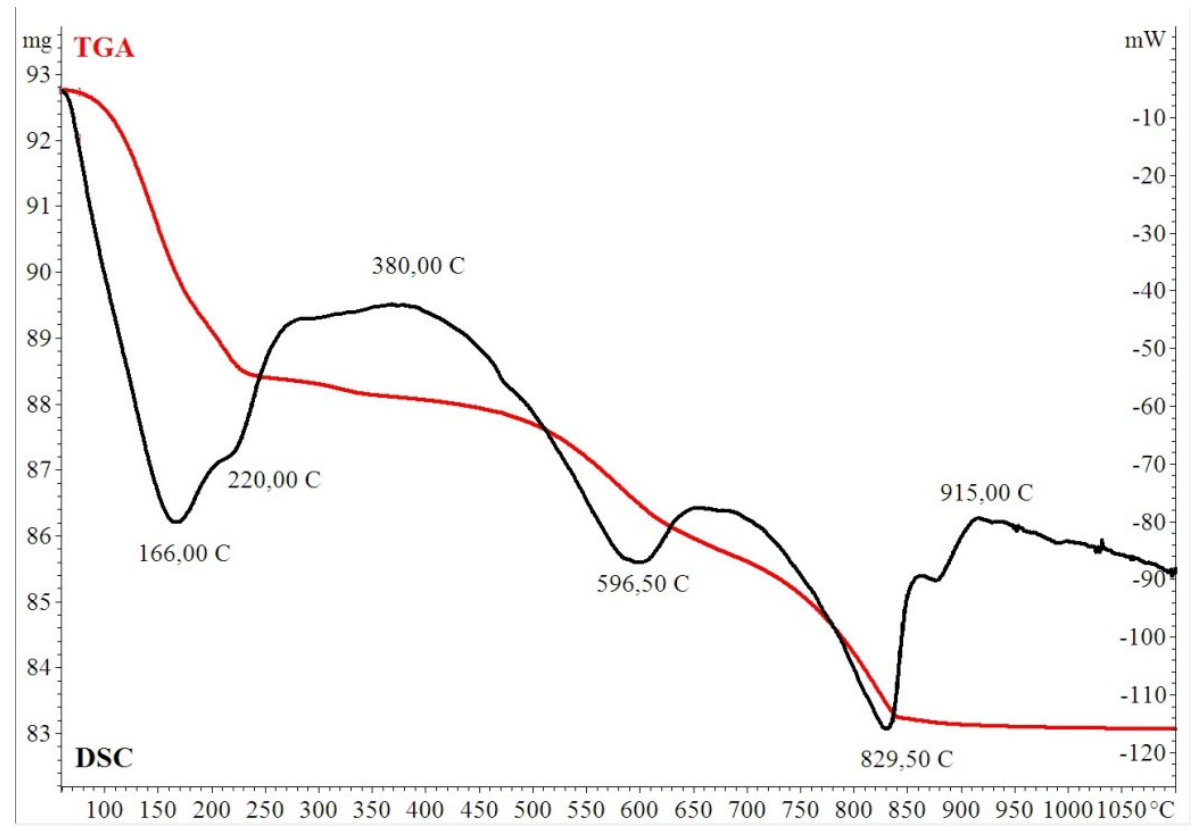

Figure 6. Differential thermal analysis of siltstone 
Thus, the found physicochemical properties of siltstone determine the possibility of its use as a structuring additive in gypsum compositions.

The conducted physical and mechanical tests of the gypsum composition samples, including 3\% of crushed siltstone, showed an increase in compressive and bending strength of the samples (Table 1) at the age of 7 days by 11.3 and 38.9, respectively, in comparison with the check composition.

Table 1. Physical and mechanical tests of the modified gypsum binder

\begin{tabular}{|c|c|c|}
\hline Siltstone content, \% & Bending strength, MPa & Compressive strength, MPa \\
\hline Check sample (0\%) & 3.96 & 10.12 \\
\hline 3 & 5.50 & 11.26 \\
\hline 7 & 5.67 & 10.64 \\
\hline
\end{tabular}

An increase in the strength of the modified gypsum binder can be due to a change in the morphology of crystalline hydrates and compaction of the structure of the binding matrix.

The analysis of the microstructure of the gypsum composition with crushed siltstone showed the intergrowth of gypsum crystals in the structure of siltstone (Figure 7a). The gypsum matrix is characterized by a dense structure with the predominance of lamellar crystals of calcium sulfate dehydrate (Figure 7b). Thus, in total, one can speak about mixed crystalline hydrate clusters (Samokhina, 2007; Panteleev \& Timashev, 1961), which lead to "ordering of structural units and homogenization of the structure as a whole, reducing its damage and, consequently, improving the mechanical characteristics of gypsum materials".

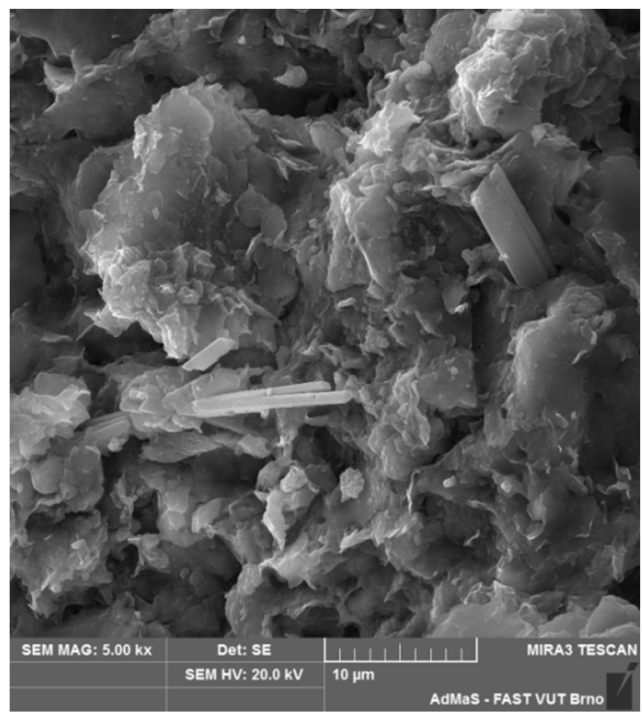

a)

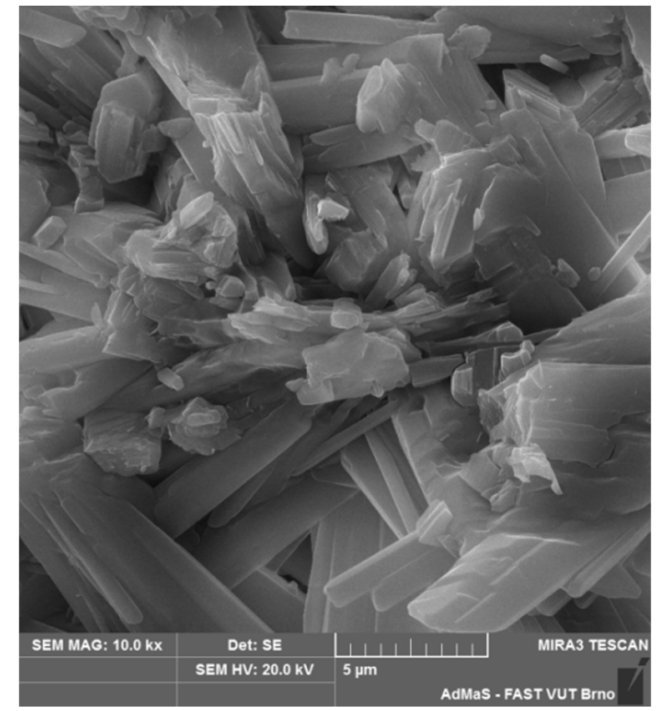

b)

Figure 7. Microstructure of the gypsum composition: (a) - intergrowth of gypsum crystals in a siltstone particle; (b) - a fragment of the microstructure of the gypsum matrix with a predominance of lamellar crystals of calcium sulfate dehydrate

Particles of crushed siltstone play the role of a "directed crystal formation substrate" (Figure 8a, b), stimulating the formation of crystalline hydrate new formations in accordance with the crystal chemical similarity of the mineral additive. At the same time, the strength of the hardened filled gypsum composition is determined by the strength of the filler and the degree of its crystal chemical similarity to the hydration products of the gypsum binder (Panteleev \& Timashev, 1961).

To determine the effect of the mineral additive on the composition of new formations of the gypsum composition, the analysis of optimized compositions was conducted using infrared spectroscopy with an IRAffinity-1 IR FT spectrometer in the frequency range of $4000-400 \mathrm{~cm}^{-1}$.

The analysis of the spectrum of the check sample (Figure 9) allowed identifying the absorption bands, which correspond to various compounds: $400-520 \mathrm{~cm}^{-1}$ indicates the presence of a $\mathrm{CaO}$ ion; the wave values in the range of $600-700 \mathrm{~cm}^{-1}$ and $1000-1040 \mathrm{~cm}^{-1}$ confirm the presence of a sulfate group $\mathrm{SO}_{4}{ }^{2-}$, absorption bands 875.68 and $1419.61 \mathrm{~cm}^{-1}$ show the presence of a carbonate grouping $\mathrm{CO}_{3}{ }^{2-}$, absorption bands in the interval $1600-1800 \mathrm{~cm}^{-1}$ are caused by deformational vibrations of water molecules, and the vibrations in the frequency range $3400-3600 \mathrm{~cm}^{-1}$ are associated with symmetric and asymmetric stretching vibrations of $\mathrm{OH}^{-}$groups in water molecules. 


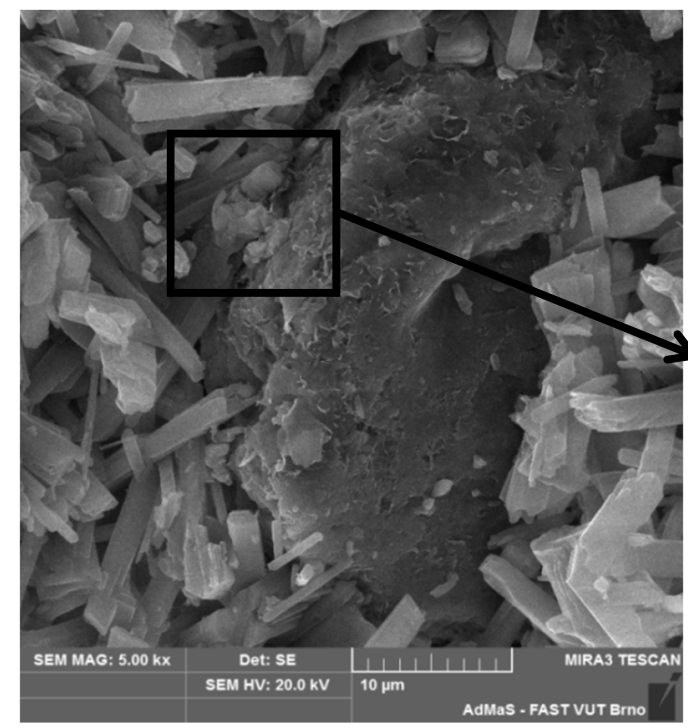

a)

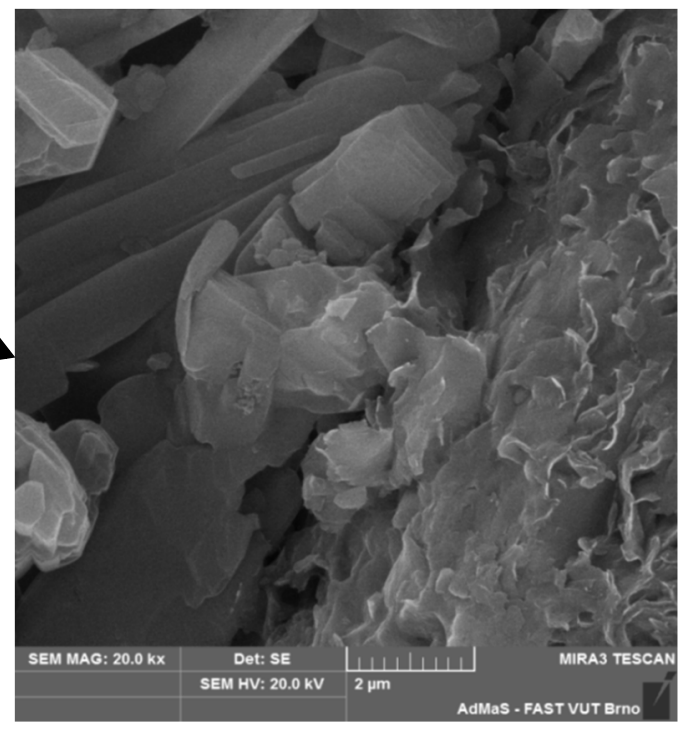

b)

Figure 8. Microstructure of the gypsum composition: (a) - crystallization of gypsum on the surface of siltstone particles; (b) - a fragment of the microstructure of the composition in the interfacial layer zone

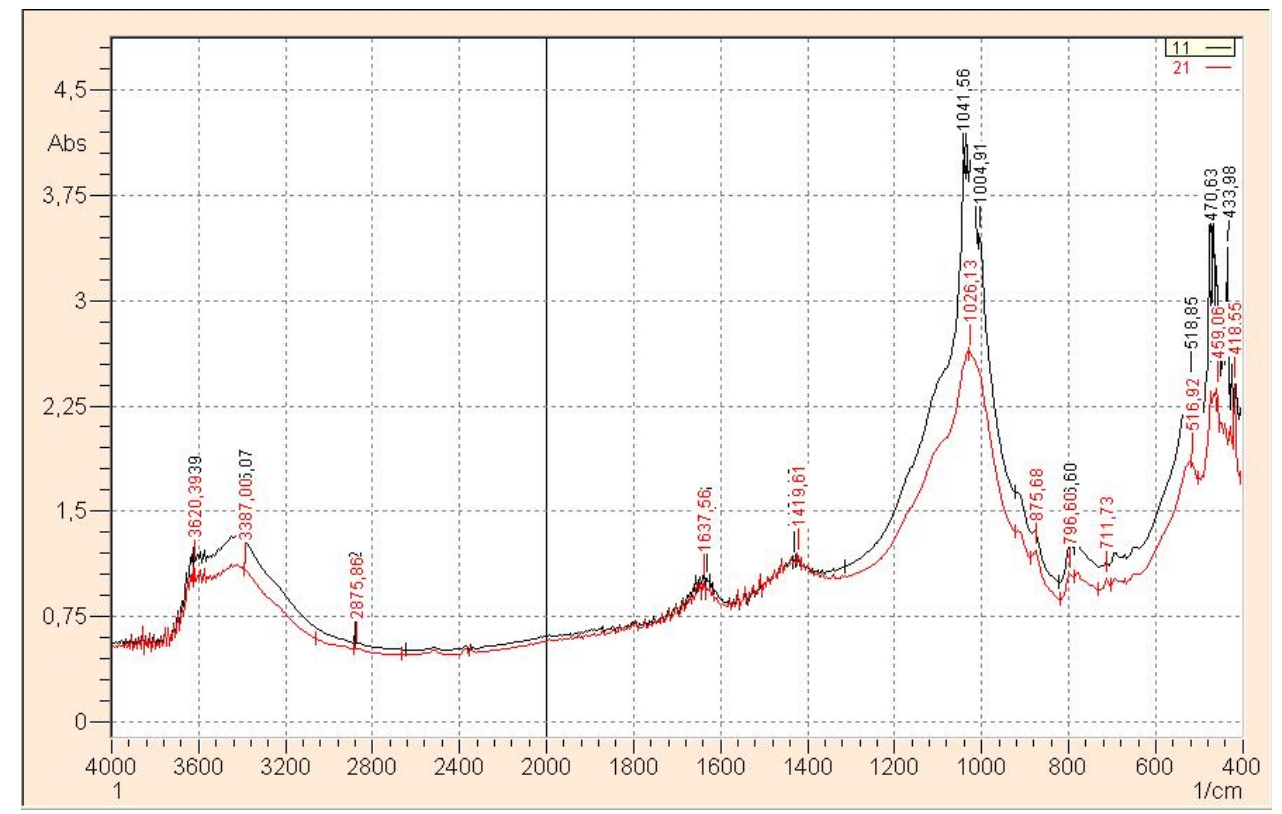

Figure 9. IR spectra: (a) the gypsum matrix without siltstone; (b) the gypsum composition with $3 \%$ of crushed siltstone

IR spectral analysis of a gypsum composition comprising 3\% siltstone showed the superposition of silicate groups on the absorption line of the sulfate group, which leads to a shift of wave numbers in the range of 1004 $1040 \mathrm{~cm}^{-1}$ and the appearance of the absorption line $v=1026.13 \mathrm{~cm}^{-1}$.

\section{Conclusions}

The studied structure and physicochemical properties of siltstone determine the possibility of its use as a structuring additive in gypsum compositions. The results of studies of the structure and properties of the gypsum composition comprising 3\% of crushed siltstone, a metamorphic rock, showed that adding crushed siltstone to gypsum compounds leads to an increase in the compressive and bending strength of the gypsum composition at the age of 7 days by 11.3 and $38.9 \%$, respectively. It is shown that adding crushed siltstone to the gypsum binder composition results in compaction of the structure of the gypsum matrix due to changes in the morphology of calcium hydrates of calcium sulfate dehydrate and homogenization of the structure as a whole, and, consequently, to improved physical and mechanical characteristics of the gypsum composition. 
Yakovlev, G.; Gordina, A.; Khritankov, V.; Khozin, V.; Shaybadullina, A.; Khazeev, D.; Bazhenova, I.;

Ivakina, A.; Saidova, Z.; Repin, A. 2019. Gypsum composition with siltstone-based mineral modifier

\section{Acknowledgements}

The study was performed within the State task by order of the Ministry of Education and Science of Russia (project 16.7823.2017/7.8). Financial supports from the Kalashnikov State University (08.06.01/18YGI) is gratefully acknowledged.

\section{References}

Arikan, M., \& Sobolev, K. (2002). The optimization of a gypsum-based composite material. Cement and Concrete Research. 32(11), 1725-1728. https://doi.org/10.1016/S0008-8846(02)00858-X

Flores Medina, N., \& Barbero-Barrera, M. M. (2017). Mechanical and physical enhancement of gypsum composites through a synergic work of polypropylene fiber and recycled isostatic graphite filler. Construction and Building Materials, 131, 165-177. https://doi.org/10.1016/j.conbuildmat.2016.11.073

Flores Medina, N., Barbero-Barrera, M. M., \& Bustamante, R. (2016). Improvement of the properties of gypsum-based composites with recycled isostatic graphite powder from the milling production of molds for Electrical Discharge Machining (EDM) used as a new filler. Construction and Building Materials, 107, 17-27. https://doi.org/10.1016/j.conbuildmat.2015.12.194

Kondratieva, N., Barre, M., Goutenoire, F., \& Sanytsky, M. (2017). Study of modified gypsum binder. Construction and Building Materials, 149, 535-542. https://doi.org/10.1016/j.conbuildmat.2017.05.140

Panteleev, A. S., \& Timashev, V. V. (1961). Hardening of binders in the presence of crystalline additives of various structures. Construction Materials, 12, 32-34.

Pervyshin, G. N., Yakovlev, G. I., Gordina, A. F., Keriene, J., Polyanskikh, I. S., Fischer, H.-B., Rachimova, N. R., \& Buryanov, A. F. (2016). Water-resistant gypsum compositions with man-made modifiers. Procedia Engineering " $12^{\text {th }}$ International Conference on Modern Building Materials, Structures and Techniques” (vol. 172, pp. 867-874), 25-26 May 2016. Vilnius, Lithuania. https://doi.org/10.1016/j.proeng.2017.02.087

Petropavlovskaya, V., Buryanov, A., Novichenkova, T., \& Petropavlovskii, K. (2018b). Gypsum composites reinforcement. IOP Conference Series: Materials Science and Engineering, 365, 032060. https://doi.org/10.1088/1757-899X/365/3/032060

Petropavlovskaya, V., Buryanov, A., Novichenkova, T., \& Petropavlovskii, K. (2018a). Gypsum composites, improved by applying basalt dust. MATEC Web of Conferences, 170, 03009. https://doi.org/10.1051/matecconf/201817003009

Samokhina, E. N. (2007). Plaster composite materials with a complex of mineral and chemical additives (Dissertation of a candidate of technical sciences). Moscow. $301 \mathrm{p}$.

Segodnik, D. N., \& Potapova, E. N. (2014). Gypsum-cement-pozzolanic binder with the active mineral additive metakaolin. Advances in Chemistry and Chemical Technology, 28(8), 77-79.

Solomatov, V. I., \& Vyrova, V. N. (1984). Physical features of the formation of the structure of composite building materials. Universities Proceedings. Construction and architecture, 8, 59-64.

Zinin, E. V., \& Sycheva, L. I. (2017). The influence of active mineral additives on the properties of gypsum-pozzolanic binders. Advances in Chemistry and Chemical Technology, 31(1), 28-30. 